\title{
Issues of Environmental Problems and World Organization Concern for the Environment
}

\author{
Ohna Timbema \\ Chuka University, Kenya
}

\begin{abstract}
This article discusses issues of Environmental Problems and World Organization Concern for the Environment. Excessive exploitation will result in a decrease in the carrying capacity of the environment. Apart from overexploitation, massive development is getting faster and faster. The rapid development that is not based on environmental knowledge has negative impacts. Environmental problems can damage ecosystems and habitats where flora and fauna live. Almost all countries have problems in dealing with waste or garbage whose numbers continue to increase every day. This problem is a major problem because it relates to the environmental conditions of a country which are also influenced by human behavior. International agreements and conferences that accompany them, relating to environmental issues. However, so far it is considered ineffective in addressing environmental problems, especially on a global scale.
\end{abstract}

Keywords: Environmental Problems, Human Behavior, World Institutions

\section{Introduction}

Environmental issues that are lively being discussed, especially in the 21st century, have become a topic of great concern. It takes humans who have a sense of responsibility and a sense of mutual need for the environment to overcome this complex environmental problem. Prudent management can also be a way out to minimize environmental damage. Environmental management wisely requires sufficient knowledge of the environment and its consequences due to human disturbance. (Gifford \& Nilsson. 2014)

Linnér \& Selin, (2013). The highlight of the world's attention to environmental problems was the holding of the United Nations Conference on the Human Environment in Stockholm (Sweden) on 5-16 June 1972 by the United Nations (UN). The conference was attended by around 113 countries and several dozen observer countries, reflecting the increasing global attention to environmental issues. At the conference, June 5 was also designated as "World Environment Day.

The idea to highlight environmental problems has been carried out by environmentalists from various countries in the world. The initial steps of the movement were more evident after the UN conference on the environment was held in Stockholm in 1972. This conference also led the world to commemorate Simple Environment Day on 5 June each year. Of course, this date does not only remind us of the importance of protecting the environment, but rather to make efforts that are one of our responsibilities as humans, which we always believe as beings who 
have wisdom in living life. Since the UN conference, a world institution that deals with environmental issues has been formed, namely the United Nations Environmental Program (UNEP).

\section{Environment and Human Behavior}

McKinney, (2002) states The environment is a place for all creatures on earth to live, especially humans. When someone talks about the environment, usually what comes to mind is the things or everything around humans because every creature has a reciprocal relationship with the surrounding nature. Humans are social creatures who cannot live without other individuals and their surroundings. This means that humans have the needs and abilities as well as habits to communicate and interact with other humans, which then forms a group of people who need each other, even making small groups in society. These small groups will later form a broad unit called state society and civilization.

Humans and their environment have a reciprocal relationship. Humans need their environment and they cannot be separated from it. A damaged living environment is an environment that can no longer carry out its function in supporting life. Human desire to improve the quality of life is something that cannot be avoided, but without wisdom in the process of achieving it, the quality of life will decline. To fulfill their daily needs, humans exploit natural resources. Along with changes in civilization, needs continue to grow both in type and in number, while the supply of natural resources is limited. Excessive exploitation will result in a decrease in the carrying capacity of the environment. Apart from overexploitation, massive development is getting faster and faster. The rapid development which is not based on environmental knowledge, has an inevitable negative impact on the quality of the surrounding environment.

Gifford \& Nilsson, (2014) states Humans and the environment have a very close relationship. The two of them influence each other. Humans have the ability to make use of the natural resources contained in them. And what happens in nature, both directly and indirectly, will have an impact on human life. Basically, God created the earth and its contents for the prosperity of mankind. The use of natural resources by humans aims to promote human welfare. In exploiting natural resources, humans must pay attention to the preservation of this nature so that the environment remains in balance to support sustainable development. Hughes, (2009) states that Human behavior towards the environment can be seen from human life before civilization to modern civilization today which is increasingly supported by sophisticated technology. However, with an increasingly modern civilization, human beings are less wise in protecting their environment. The quality of the environment is now decreasing from year to year. This is caused by an imbalance between the use and protection of the environment. The increase in vehicles from year to year has increased significantly. Thus, it causes a decrease in the quality of fresh air, especially in big cities.

\section{Environmental issues faced}

Garbage has become a classic problem for every country around the world. Almost all countries have problems in dealing with waste or garbage whose numbers continue to increase every day. This problem is a major problem because it relates to the environmental conditions of a country. Therefore, currently many countries have started reuse and recycle programs for existing waste to overcome this problem. 
In our own country, waste is a problem that has never been resolved. Even though our government has also implemented a reuse and recycle program, the environmental and waste problems in our country have not been resolved. Even the problems in our country are branching out and spreading to various other aspects, thus affecting environmental damage.

In fact, the source that causes environmental problems is the act of humans who in their activities do not care about the balance and harmony of the environment. Humans who always try to fulfill their needs and desires will go beyond the ability of the environment to support life. Activities in the form of excessive exploitation cause disruption of the balance and harmony of the environment.

Environmental damage due to human factors Humans as the ruler of the environment on earth play a major role in determining environmental sustainability, what humans do is not balanced with thinking about the future of the life of the next generation. Humans are a category of factors that cause environmental damage.

\section{Pollution}

Yu et al. (2011) argues Air, water and land pollution took millions of years to recover. Industrial and motor vehicle exhausts are the number one pollutant. crc press. Heavy metals, nitrates and plastics are poisons that are responsible for pollution. Meanwhile water pollution is caused by oil spills, acid rain, city runoff; air pollution is caused by various gases and toxins released by industry and factories and the burning of fossil fuels. soil pollution is mainly caused by industrial waste which deprives the soil of essential nutrients.

\section{Plastic Waste}

Comăniță et al. (2016) states Plastic waste dumped into the sea can harm living things and the surrounding ecosystem. This is because plastics can break down and turn into microplastics and nanoplastics. Both types are very small plastic and are often accidentally consumed by fish because of their eye-catching color. The micro and nano plastics settle in the fish's bodies which we ultimately consume. Plastic bags are single-use items with irresponsible postconsumption activities. Plastic bags that are thrown away carelessly can clog up gutters and water bodies, are eaten by animals and damage ecosystems in rivers and oceans. Burnt plastic bags can cause air pollution and respiratory problems. In addition, plastic bags used as food containers have the potential to harm human health because the toxins in plastic bags can be transferred to food. Plastic bags will break down hundreds to thousands of years later. Plastic bags that are claimed to be environmentally friendly will decompose for a long time and will still become trash. Moreover, because it is quickly broken down into microplastics, it will be easier to pollute the environment.

\section{Loss of Biodiversity}

Petrenko et al. (2016). Environmental problems can damage ecosystems and habitats where flora and fauna live. For example, deforestation, clearing land for oil palm, destroys the habitat of Orangutans, so their current numbers are quite alarming. Not only orangutans, other living things that depend on the forest for their lives are also displaced so that in the end they enter human territory. Ecosystem imbalances take hundreds of years, thousands of years, even millions of years to balance again. Plastic bags (and other types of plastic) are difficult to break down on the ground because of their long carbon chains, making them difficult for microorganisms to break down. 


\section{Global Warming}

Vitousek, (1994) states that Global warming is starting to be felt all over the world. The irregularity in the timing of the dry and rainy seasons is one of the obvious symptoms of global warming. Global warming causes water temperatures to rise. Many corals have experienced bleaching due to conditions of rising water temperatures in recent years. The ozone layer is an invisible layer of protection around the planet that protects us from the sun's harmful rays. The depletion of the essential Ozone layer in the atmosphere is caused by pollution caused by chlorine and bromine which are found in Chloro-chlorine carbon (CFC's). Once these poisonous gases reach the upper atmosphere, they cause holes in the ozone layer, the largest of which is over Antarctica. CFCs are banned in many industries and consumer products. The ozone layer is valuable because it prevents harmful UV radiation from reaching the earth. This is one of the most important environmental problems today. The second result of global warming is climate change. Irregular weather patterns have begun to show the effects of global warming. Increased rainfall in the form of rain has been noted in arctic regions and deserts. Increased global warming will cause more evaporation which will cause more rain. Animals and plants cannot easily adapt to increased rainfall. Plants can die and animals can migrate to other areas. This can cause the entire ecosystem to change completely and rapidly. Beyond human ability to adapt.

\section{World Organization Concern for the Environment}

The agreement on environmental issues which are trans-border issues was first discussed at the meeting in Rio de Janeiro in 1992. The meeting was entitled The U.N. Conference on Environment and Development. Since then, many agreements and meetings that discuss environmental issues have been held. The meeting held in Rio de Janeiro was not only attended by UN member states, but more importantly, this meeting also presented parallel meetings with non-state actors in observing environmental issues and problems in the sustainable development approach. Greenpeace The organization based in Amsterdam, the Netherlands, is one of the most popular in the world and is the toughest against environmental destroyers. Especially with regard to environmental damage due to various pollution that threaten survival. Then the World Wildlife Fund (WWF) For environmentalists, they must be familiar and familiar with this organization bearing the panda logo. It is recorded that there are about 5 million members worldwide. The concentration of this institution is to preserve animals from extinction. Imagine, what the world would be like if all animals were extinct. The World Conservation Monitoring Center (WCMC) is the executive body of the United Nations Environment Program (UNEP), headquartered in Cambridge, England.

WCMC has been part of UNEP since 2000, and is authorized to address and support biodiversity for policy development and implementation. The World Conservation Monitoring Center was previously an independent organization jointly regulated by IUCN, UNEP, and WWF, founded in 1988. WCMC activities include handling biodiversity, support for international conventions such as the Convention of Biological Diversity (CBD) and the Convention of International Trade in Endangered. Species of Wild Fauna and Flora (CITES).

Actually there have been many International Agreements and conferences that accompany them, relating to environmental issues. However, so far it is considered ineffective in addressing environmental problems, especially on a global scale. These agreements are considered too normative by environmental activists who are involved and directly involved in dealing with environmental issues and problems in the real world. 


\section{Conclusion}

Prudent management can also be a way out to minimize environmental damage. Environmental management wisely requires sufficient knowledge of the environment and its consequences due to human disturbance. Humans and their environment have a reciprocal relationship. Humans need their environment and they cannot be separated from it. A damaged living environment is an environment that can no longer carry out its function in supporting life. International agreements and conferences that accompany them, relating to environmental issues. However, so far it is considered ineffective in addressing environmental problems, especially on a global scale.

\section{References}

Comăniță, E. D., Hlihor, R. M., Ghinea, C., \& Gavrilescu, M. (2016). OCCURRENCE OF PLASTIC WASTE IN THE ENVIRONMENT: ECOLOGICAL AND HEALTH RISKS. Environmental Engineering \& Management Journal (EEMJ), 15(3).

Gifford, R., \& Nilsson, A. (2014). Personal and social factors that influence pro-environmental concern and behaviour: A review. International Journal of Psychology, 49(3), 141-157.

Gifford, R., \& Nilsson, A. (2014). Personal and social factors that influence pro-environmental concern and behaviour: A review. International Journal of Psychology, 49(3), 141-157.

Hughes, J. D. (2009). An environmental history of the world: humankind's changing role in the community of life. Routledge.

Linnér, B. O., \& Selin, H. (2013). The United Nations Conference on Sustainable Development: forty years in the making. Environment and Planning C: Government and Policy, 31(6), 971-987.

McKinney, M. L. (2002). Urbanization, Biodiversity, and ConservationThe impacts of urbanization on native species are poorly studied, but educating a highly urbanized human population about these impacts can greatly improve species conservation in all ecosystems. Bioscience, 52(10), 883-890.

Petrenko, C., Paltseva, J., \& Searle, S. (2016). Ecological impacts of palm oil expansion in Indonesia. Washington (US): International Council on Clean Transportation.

Yu, M. H., Tsunoda, H., \& Tsunoda, M. (2011). Environmental toxicology: biological and health effects of pollutants.

Vitousek, P. M. (1994). Beyond global warming: ecology and global change. Ecology, 75(7), 1861-1876. 